\title{
The Current Landscape of Program Theorizing
}

\author{
Jane Whynot \\ University of Ottawa \\ Steve Montague \\ Performance Management Network \\ Sebastian Lemire \\ University of California, Los Angeles
}

There is a long and rich tradition of developing and using program theories in evaluation. This commitment is reflected clearly within the Canadian federal government evaluation context. Despite two evaluation policy updates in the last decade, five out of the six accompanying guidance materials explicitly posit theorizing as foundational to evaluation efforts, whether addressing the development of performance measurement strategies (Treasury Board Secretariat, 2010), assessing resource utilization (Treasury Board Secretariat, 2013), rapid impact assessment (Treasury Board Secretariat, 2017), evaluating horizontal initiatives (Treasury Board Secretariat, 2012a), or program theory itself (Treasury Board Secretariat, 2012b). Theory has permeated the federal government evaluation landscape, the expectation clear that theorizing should underpin evaluation conversations. Expectations are still shrouded, however, by the various ways in which program theorizing can, and should, occur.

The overarching aim of this special issue is to promote reflective practice in program theorizing: to expand and strengthen both the conceptual and technical foundations of program theories in evaluation and to establish theory development and use as a fundamental tenet of evaluative thinking more broadly. Driving motivations for this special edition stem from decades of applied evaluation experience and cumulative, consistent reflection on behalf of the scholar practitioner guest editors who probe at the paradoxes of program theorizing and its unrealized potential to achieve many of its promised benefits. Underpinning this objective is the critical, accompanying shift in thinking, moving from "program theories in evaluation is a good idea" to "these are good ideas for program theorizing."

To be sure, the use of program theories in evaluation is nothing new. Early program theory inklings can be traced back to the work of Donald Kirkpatrick (1959), Edward Suchman (1967), and Daniel Stufflebeam (1967), among others. However, the blossoming of program theories came with the formalization of theory-based evaluation in the 1980s (Bickman, 1987; Chen \& Rossi, 1980, 1983). In Canada, program theory was embodied in component profiles, program models, and causal models, eventually becoming known as models that covered a review of the "rationale" of a program. These models were a fundamental piece 
of the Canadian government's nascent evaluation guidance in the early 1980s (Treasury Board of Canada Comptroller General, 1981). Since then, a steady flow of articles, special issues, and books dedicated to the topic of program theories specifically, and theory-based evaluation more generally, has emerged. The aspects of program theorizing covered in these contributions range broadly, including reflections on different types of program theories (Chen \& Rossi, 1980, 1983; Funnell \& Rogers, 2011), what constitutes good or even just decent program theory (Mayne, 2015, 2017; Weiss, 1997), the role and purpose of program theory in evaluation (Bickman, 1987, 1990; Donaldson, 2007; Funnell \& Rogers, 2011), how program theories are used in practice (Bickman, 1987; Coryn, Noakes, Westine, \& Schroter, 2011), and how to test and use program theories (Bickman, 1987, 1990; Rogers, Hacsi, Petrosino, \& Huebner, 2000), to name but a few. The interest in describing and understanding the underlying logic of social programs is pervasive and persistent.

This is not the place to provide a comprehensive and detailed review of the historical roots and developments of program theorizing in evaluation (see Funnell \& Rogers, 2011, for an exemplary review). Suffice it to say that program theorizing continues to gain traction among evaluation scholars and practitioners, advancing our practice in new directions. Recently, in reflecting on past and present trends in theory-based evaluation, Brousselle and Buregeya (2018) argued for the rise of a new generation of theory-based evaluation reaching beyond summaries of "plausibility, effect and implementation analysis" to address the challenges and limitations presented within current program theory thinking to address complex social issues, and the associated complexity grounded in open systems, which are in turn embedded in multiple social systems (Brousselle \& Buregeya, 2018, pp. 163-164). As Brousselle and Buregeya rhetorically ask, "How to deal with uncertainty created by interdependency among numerous actors who are constantly evolving and adapting? How to adapt to non-linear and sometimes unpredictable relationships? How to assess emergent and unanticipated outcomes resulting from relationships that are sometimes non-linear?" These are but a few of the key questions around which this next generation of theory-based evaluation revolves.

Anticipating this next generation of program theorizing, the special issue offers six articles that all in their own way illustrate specific strategies for enhancing the conceptual development, empirical validation, and practical use of program theories in evaluation practice.

In the first article, Andrew Koleros and John Mayne propose and illustrate the use of nested actor-based theories of change. Based on an application of a contribution analysis of a complex police-reform program, the authors compellingly argue that "the strength of a contribution claim is only as good as the ToC [theory of change] being used" (p. 295). Toward building stronger and evaluable theories of change, the authors illustrate the development of a nested theory of change, wherein the complexity underlying a general theory of change for a program is further unfolded in a subset of nested actor-based theories of change, each of 
which provides more fine-grained details on select aspects of the overarching theory of change for the program.

In the second article, Montague argues that further systematic coding and analysis of change theories, action theories, and in particular their combinations in programs could produce useful insights for both evaluation and public-policy decision making. Motivated by the adage that the whole may be greater than the sum of the parts in terms of explanation, Montague cogently argues for further codification of both implementation/action theories and change theories, whereby both can be considered and empirically examined in tandem as part of theory-based evaluations.

Freer and Lemire, in the third article, continue the focus on the role and purpose of different types of theories. Writing in the context of development evaluation, the authors argue that while logframes and a theory of changes are complementary aids of thinking, they are typically developed in isolation from one another. As a result, and while the two models might display similarities and commonalities, logframes and theories of change are perceived as serving different roles and as reporting against different aspects of a program, and are not seen as complementary. Informed by a real-world example, the authors propose five steps toward integrating these tools in program planning and evaluation.

Jane Whynot and the Chairs for Women in Science and Engineering, including Catherine Mavriplis, Annemieke Farenhorst, Eve Langelier, Tamara Franz-Odendaal, and Lesley Shannon, share the results of their practical and conceptual efforts integrating gender in program theory. They embrace theory knitting: drawing on and situating gendered expertise and experiences to address measurement and evaluation efforts in developing program theory to address the under-representation, recruitment, retention, and promotion of girls and women in STEM.

Framing programs as "dynamic processes," Sanjeev Sridharan and April Nakaima argue that "planning for sustainability needs to be a critical aspect of the impact chains of all theories of change" (p. 375). This involves recognizing that the impact pathways may differ across different participants and even change over time. Informed by an evaluation of an empowerment program for immigrant women, the authors compare and contrast a linear mechanical view of the change process with a view that explicitly incorporates planning for sustainability, argue for the important role of planning for sustainability, and consider the implications of planning for sustainability for the practice of theory-driven evaluation.

Motivated by the surge of interest in mixed-methods and theory-based systematic reviews, Lemire and Christie promote and illustrate an application of meta-modeling, a theory-based synthesis approach. Combining meta-analysis and qualitative comparative analysis, meta-modeling offers a systematic and transparent approach to developing meta-models of programs across a broad range of existing studies. Based on a practical application of meta-modeling on Housing First, the authors call for further attention to and developments in theory-based synthesis approaches. 
In the concluding article of this special issue, the guest editors-Sebastian Lemire, Jane Whynot, and Steve Montague-scale the proverbial soapbox and declare a call for action to strengthen and promote reflective practice in program theorizing. Motivated by their own successes and failures, and inspired and informed by the significant contributions comprising the present special issue, the guest editors formulate ten declarations that collectively serve as a motivating and useful manifesto for the future of program theorizing in evaluation.

\section{REFERENCES}

Bickman, L. (1987). Using program theory in evaluation. In L. Bickman (Ed.), Using program theory in evaluation: New directions for program evaluation (Vol. 33, pp. 5-17). San Francisco, CA: Jossey-Bass.

Bickman, L. (1990). Advances in program theory: New Directions for Program Evaluation (Vol. 47). San Francisco, CA: Jossey-Bass.

Brousselle, A., \& Buregeya, J. (2018). Theory-based evaluations: Framing the existence of the new theory in evaluation and the rise of the 5th generation. Evaluation, 24(2), 153-168. https://doi.org/10.1177/1356389018765487

Chen, H.-T., \& Rossi, P. H. (1980). The multi-goal, theory driven approach to evaluation: A model linking basic and applied social science. Social Forces, 59(1), 106-122. https:// doi.org/10.2307/2577835

Chen, H.-T., \& Rossi, P. H. (1983). Evaluating with sense: The theory-driven approach. Evaluation Review, 7(3), 283-302. https://doi.org/10.1177/0193841X8300700301

Coryn, C. L. S., Noakes, L. A., Westine, C. D., \& Schroter, D. (2011). A systematic review of theory-driven evaluation practice from 1990 to 2009. American Journal of Evaluation, 32(2), 199-226. https://doi.org/10.1177/1098214010389321

Donaldson, S. I. (2007). Program theory-driven evaluation science: Strategies and applications. Mahwah, NJ: Lawrence Erlbaum Associates.

Funnell, S. C., \& Rogers, P. J. (2011). Purposeful program theory: Effective use of theories of change and logic models. San Francisco, CA: Jossey-Bass.

Kirkpatrick, D. (1959). Techniques for evaluation training programs. Journal of the American Society of Training Directors, 13(11), 21-26.

Mayne, J. (2015). Useful theory of change models. The Canadian Journal of Program Evaluation, 30(2), 119-142.

Mayne, J. (2017). Theory of change analysis: Building robust theories of change. The Canadian Journal of Program Evaluation, 32(2), 155-173. https://doi.org/10.3138/ cjpe. 31122

Rogers, P. J., Hacsi, T. A., Petrosino, A., \& Huebner, T. A. (Eds.). (2000). Program theory in evaluation: Challenges and opportunities. New directions for evaluation, 87. San Francisco, CA: Jossey-Bass.

Stufflebeam, D. S. (1967). The use and abuse of evaluation in title III. Theory into Practice, 6(3), 126-133. https://doi.org/10.1080/00405846709542071 
Suchman, E. (1967). Evaluative research: Principles and practice in public service and social action programs. New York, NY: Russell Sage Foundation.

Treasury Board of Canada Comptroller General. (1981). Guide on the program evaluation function. Retrieved from https://www.tbs-sct.gc.ca/cee/pubs/guide1981-eng. asp\#archived

Treasury Board Secretariat. (2010). Supporting effective evaluations: A guide to developing performance measurement strategies. Retrieved from https://www.canada.ca/en/ treasury-board-secretariat/services/audit-evaluation/centre-excellence-evaluation/ guide-developing-performance-measurement-strategies.html

Treasury Board Secretariat. (2012a). Guidance on the governance and management of evaluations of horizontal initiatives. Retrieved from https://www.canada.ca/en/ treasury-board-secretariat/services/audit-evaluation/centre-excellence-evaluation/ guidance-governance-management-evaluations-horizontal-initiatives.html

Treasury Board Secretariat. (2012b). Theory-based approaches to evaluation: Concepts and practices. Retrieved from https://www.canada.ca/en/treasury-board-secretariat/ services/audit-evaluation/centre-excellence-evaluation/theory-based-approachesevaluation-concepts-practices.html

Treasury Board Secretariat. (2013). Assessing program resource utilization when evaluating federal programs. Retrieved from https://www.canada.ca/en/treasuryboard-secretariat/services/audit-evaluation/centre-excellence-evaluation/ assessing-program-resource-utilization-evaluating-federal-programs.html

Treasury Board Secretariat. (2017). Guide to rapid impact evaluation. Retrieved from https://www.canada.ca/en/treasury-board-secretariat/services/audit-evaluation/ centre-excellence-evaluation/guide-rapid-impact-evaluation.html

Weiss, C. H. (1997). How can theory-based evaluation make greater headway? Evaluation Review, 21(4), 501-524. https://doi.org/10.1177/0193841X9702100405 